\title{
A Simplified Uniaxial Stress-strain Curve of Concrete and Its Application in Numerical Simulation
}

\author{
Lou Yafei ${ }^{1}$, Zou Tao $^{1 *}$, Yang Jie ${ }^{1}$, Jiang Tao ${ }^{1}$, Zhang Qingfang ${ }^{1}$, Hong Hexuan ${ }^{1}$ \\ ${ }^{1}$ College of Ocean and Civil Engineering, Dalian Ocean University, Dalian 116023, China
}

\begin{abstract}
Determining the constitutive model is a key procedure in numerical simulation of concrete structures. The uniaxial stress-strain curve is important information to determine the concrete constitutive model. This paper provided a simplified stress-strain curve of concrete that can be used in simulation. The comparison between Chinese Code and the simplified curve shows that the simplified curve of uniaxial compression is close to the code value. Numerical simulation of concrete beams show that the simplified curve proposed has high computational efficiency and good convergence.
\end{abstract}

\section{Introduction}

Recently, large-scale FEM software, such as ABAQUS, ANSYS, etc, has been used in various fields. In a numerical simulation analysis, the uniaxial stress-strain curve is an important information to define the constitutive model of material, which affects the accuracy and efficiency of the analysis. Some different uniaxial sterss-strain expressions were proposed in researches on mechanical properties of concrete ${ }^{[1-5]}$. The corresponding expressions are also given in Chinese Code for Design of Concrete Structures ${ }^{[6]}$. In the absence of test data, these expressions can be used to represent the uniaxial stress-strain relationship of concrete. The expressions in the code are used more widely, but they are complicated and the tangent modulus is not diminishing in the descending stage. So the researcher and engineer must modify the stress-strain curve for structural simulation in FEM, such as a simulation with Concrete Damaged Plasticity Model (CDP model) in ABAQUS. For improving the efficiency, convergence and convenience of simulation, a more simple and convenient expression based on Chinese code was proposed in this paper.

\section{Uniaxial Stress-strain Curve for Concrete}

\section{1 The curve for uniaxial compression}

The existing test data show that the stress-strain curve of concrete under uniaxial compression can be divided into two segments: ascending stage and descending stage ${ }^{[1-5]}$. $\mathrm{Yan}^{[7]}$ divided the curve into five stages according to the uniaxial compression test data of $\mathrm{C} 30 \sim \mathrm{C} 60$ concrete as shown in Fig 1, where the first stage $(\mathrm{OA})$ was linear elastic ascending, the second stage $(\mathrm{AB})$ was nonlinear ascending, the third stage $(\mathrm{BC})$ was nonlinear descending the fourth stage $(C D)$ was reverse bending, the fifth stage was flatten out because of eventual damage of concrete. Shen ${ }^{[8]}$ divided the ascending stage into three parts according to the development of micro-cracks in concrete under uniaxial compression, namely the $\mathrm{AB}$ stage in Fig 1 was divided into two parts ( $\mathrm{AB}^{\prime}$ and $\left.\mathrm{B}^{\prime} \mathrm{B}\right)$. In stage $\mathrm{OA}$, there is no obvious development of micro-cracks in concrete, and the material shows elastic characteristics; in stage $\mathrm{AB}^{\prime}$ micro-cracks begin to develop obviously; in stage B'B the number and width of micro-cracks increase sharply, the material shows plastic characteristics.

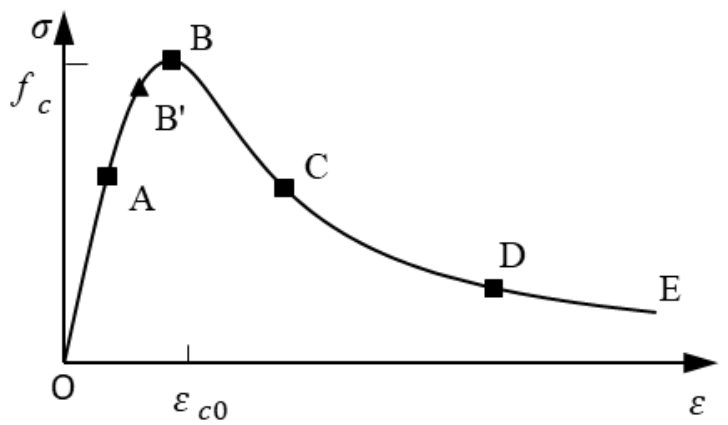

Fig. 1. The stress-strain curve of concrete in uniaxial compression

According to damaged characteristics of concrete, a simplified stress-strain curve of concrete under uniaxial compression was proposed having four linear stage as shown in Fig. 2. 


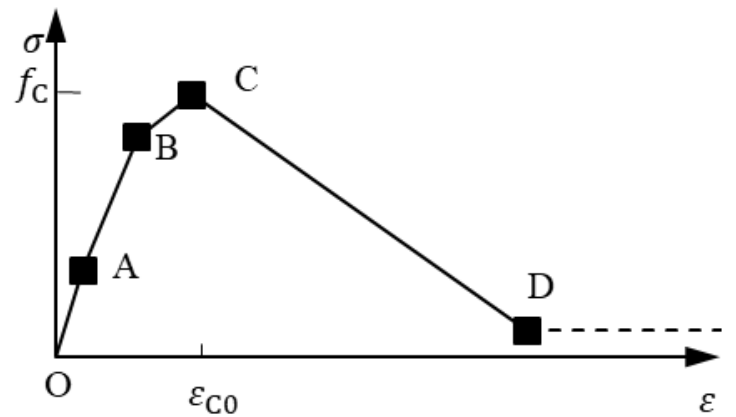

Fig. 2. The simplified stress-strain curve of concrete under uniaxial compression

\section{2 The curve for uniaxial tension}

The stress-strain curve of concrete under uniaxial tension is similar to that under uniaxial compression. It can also be divided into two stages: ascending stage and descending stage ${ }^{[9]}$. But its ascending stage shows more obvious linear elastic characteristics. The ascending stage of uniaxial tensile stress-strain curve is considered as straight line in common concrete constitutive model.

In the paper a simplified stress-strain curve of concrete under uniaxial tension was proposed having two linear stage as shown in Fig. 3. $\varepsilon_{\mathrm{t} 0}$ and $f_{t}$ are peak tensile strain and peak tensile stress respectively.

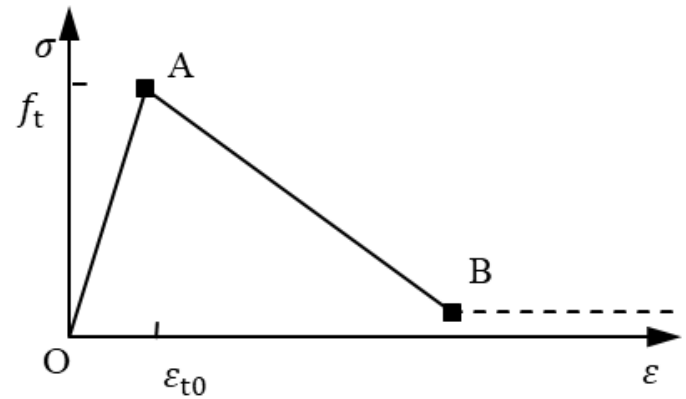

Fig. 3. The simplified stress-strain curve of concrete under uniaxial tension

The Value of each point in Fig. 2 and Fig. 3 can be determined with test data under uniaxial load. If a test data is difficult to obtained, the value can be also determined with the full stress-strain curve due to Code.

In this paper, a simple calculation method for each control point is given based on the analysis of the full stress-strain curve of concrete, combined with the existing test results and the requirements of numerical analysis.

\section{Values at points on the simplified curve}

\section{1 Compression}

\section{1. 1 Point $A$}

Point A is proportional limit, that is, the critical point between the elastic and plastic stages.

Figure 4 shows the relationship between $X$ and $\boldsymbol{E}_{\mathrm{t}}$, where $X$ is the ratio of strain to peak compressive strain, $\boldsymbol{E}_{\mathrm{t}}$ is tangent modulus of ascending stage. Both $\boldsymbol{E}_{\mathrm{t}}$ and $X$ were calculated with expressions in Code.

The point where tangent modulus decreases significantly in Fig 4 is the proportional limit point. As can be seen in Fig 4, the higher the concrete strength, the greater the $X$ value of its proportional limit point.

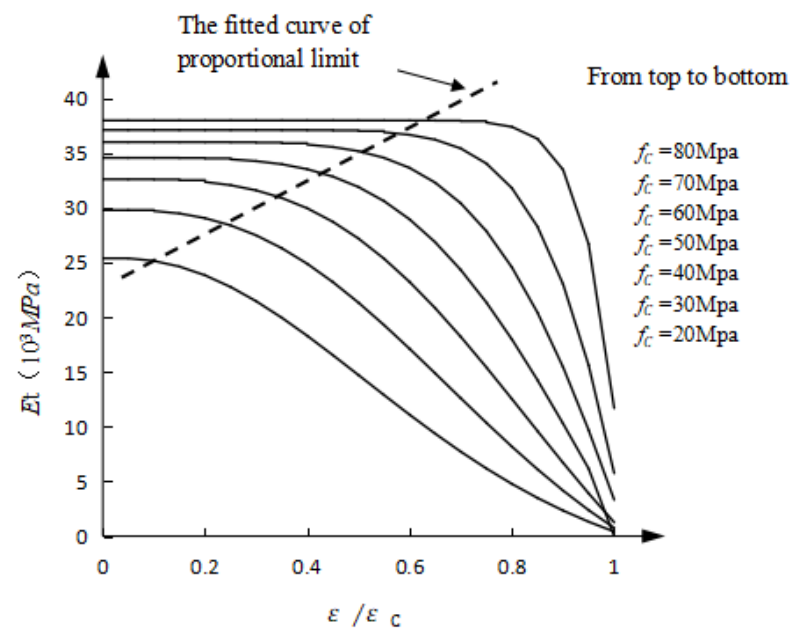

Fig. 4. The tangent modulus of curves in code

If $X_{\mathrm{A}}$ is denoted as the $X$ value of the proportional limit point $\mathrm{A}, X_{\mathrm{A}}$ of concrete with different strengths are fitted to obtain:

$$
X_{A}=0.01 f_{c}-0.1
$$

Where $f_{\mathrm{c}}$ is compressive strength of concrete $\left(\mathrm{N} / \mathrm{mm}^{2}\right)$.

The stress and strain of point A can be denoted as formula (2)

$$
\left\{\begin{array}{l}
\varepsilon_{\mathrm{A}}=\left(0.01 f_{c}-0.1\right) \varepsilon_{\mathrm{c} 0} \\
\sigma_{\mathrm{A}}=\left(0.01 f_{c}-0.1\right) E_{C} \varepsilon_{\mathrm{c} 0}
\end{array}\right.
$$

Where $E_{\mathrm{c}}$ is elastic modulus $\left(\mathrm{N} / \mathrm{mm}^{2}\right), \varepsilon_{\mathrm{A}}$ is strain at point $\mathrm{A}, \sigma_{\mathrm{A}}$ is stress at point $\mathrm{A}\left(\mathrm{N} / \mathrm{mm}^{2}\right)$.

\section{1. 2 Point B}

The strain at point $\mathrm{B}, \varepsilon_{\mathrm{B}}$, takes the intermediate value of strain at point $\mathrm{A}$ and peak point (point $\mathrm{C}$ ). The stress at point $\mathrm{B}, \sigma_{\mathrm{B}}$, is calculated by the method in Code.

$\varepsilon_{\mathrm{B}}$ and $\sigma_{\mathrm{B}}$ can be expressed as Formula (3) and Formula (4). 


$$
\left\{\begin{array}{c}
\varepsilon_{\mathrm{B}}=\left(0.005 f_{c}+0.45\right) \varepsilon_{\mathrm{c} 0} \\
\sigma_{\mathrm{B}}=\frac{n\left(0.005 f_{c}+0.45\right)}{n-1+\left(0.005 f_{c}+0.45\right)^{n}} f_{c} \\
n=\frac{E_{c} \varepsilon_{c 0}}{E_{c} \varepsilon_{c 0}-f_{c}}
\end{array}\right.
$$

Where $n$ is positive.

For high-strength concrete, when the difference between the tangent modulus of $\mathrm{AB}$ stage and $\mathrm{OA}$ stage is small, point B can be omitted to improve the efficiency of numerical calculation.

\section{1. 3 Point $C$}

$\mathrm{C}$ is the peak point, the stress and strain are:

$$
\left\{\begin{array}{l}
\varepsilon_{\mathrm{C}}=\varepsilon_{\mathrm{C} 0} \\
\sigma_{\mathrm{C}}=f_{c}
\end{array}\right.
$$

\section{1. 4 Point $D$}

At point $\mathrm{D}$, the eventual failure happened. Experimental study in reference [3] shows that there is still a certain residual strength after the eventual failure happened, and the residual strength is $0.15 f_{\mathrm{c}} \sim 0.25 f_{\mathrm{c}}$. Experimental data in reference [7] shows that the residual strength is 0 . $1 f_{\mathrm{c}} \sim 0.3 f_{\mathrm{c}}$. In this paper the stress at point $\mathrm{D}$ is $0.1 f_{\mathrm{c}}$.

Since the descending stage is represented by a straight line in this paper, the influence of the inflection point (point C) in Fig. 1 is not considered. If the strain value of point $\mathrm{D}$ is too large, the stress of the descending stage will be overestimated. Based on the experimental results of reference [3] and reference [7] and the stress-strain relationship in the code, it is suggested that the stress-strain at point $\mathrm{D}$ be calculated by the following formula:

$$
\left\{\begin{array}{l}
\varepsilon_{\mathrm{D}}=k \varepsilon_{\mathrm{C} 0} \\
\sigma_{\mathrm{D}}=0.1 f_{c}
\end{array}\right.
$$

Where $k$ is a correction factor for strain at point. $k=4 \sim 6$ when $f_{\mathrm{c}}<50 \mathrm{~N} / \mathrm{mm}^{2}$, and $k=3$ when $f_{\mathrm{c}} \geq 50 \mathrm{~N} / \mathrm{mm}^{2}$.

\section{1. 5 Peak compressive strain}

In Chinese code the value of peak compressive strain $\varepsilon_{\mathrm{c} 0}$ is Calculated relating to concrete strength, as shown in formula (7).

$$
\varepsilon_{\mathrm{c} 0}=\left(700+172 \sqrt{f_{c}}\right) \times 10^{-6}
$$

The European code takes $0.0022^{[10]}$, as the value of $\varepsilon_{\mathrm{c} 0}$, and the Japanese code takes $0.002^{[11]}$. The literature [7] consider that the peak compressive strain does not change with the strength of concrete.

In this paper it is suggested that the value of peak compressive strain $\varepsilon_{\mathrm{c} 0}$ is 0.002 and 0.0022 , when $f_{\mathrm{c}}<$ $50 \mathrm{~N} / \mathrm{mm}^{2}$ and $f_{\mathrm{c}} \geq 50 \mathrm{~N} / \mathrm{mm}^{2}$ respectively.

\section{2 Tension}

\section{2. 1 Point $A$}

Stress and strain at point $\mathrm{A}$ are calculated by formula (8)

$$
\left\{\begin{array}{l}
\varepsilon_{\mathrm{A}}=f_{t} / E_{c} \\
\sigma_{\mathrm{A}}=f_{t}
\end{array}\right.
$$

Where $f_{\mathrm{t}}$ is tensile strength $\left(\mathrm{N} / \mathrm{mm}^{2}\right)$.

\section{2. 2 Point $B$}

Point B is the stress and strain when the concrete breaks entirely. Based on the assumption of diffusion cracking, strain and stress at point B are expressed in the form of formula (9) in this paper.

$$
\left\{\begin{array}{l}
\varepsilon_{\mathrm{B}}=u_{c k} / L_{e} \\
\sigma_{\mathrm{B}}=k f_{t}
\end{array}\right.
$$

Where $u_{\mathrm{ck}}$ is the crack width when the material is broken entirely, Le is the shortest edge of the element, and $\mathrm{k}$ is the factor for residual stress.

The results of uniaxial tension test in reference [9] show that $u_{\mathrm{ck}}$ is $0.4 \mathrm{~mm}$. This paper suggests that the value of $u_{\text {ck }}$ is $0.3 \sim 0.5 \mathrm{~mm}$ for conventional concrete and $0.1 \sim 0.3 \mathrm{~mm}$ for high-strength concrete $[9,12]$. When the element size is large, the influence of deformation in the non-cracking zone should be considered, and the value of $u_{\mathrm{ck}}$ can be appropriately increased.

The material cannot be stressed after breaking, but the converge is extremely difficult to obtained for a numerical analysis with a zero tensile stress state. The range of $0.01 \sim 0.02$ is recommended for $\mathrm{k}$ in this paper.

\section{Comparison between curves}

Here three cases were discussed that the compressive strength $f_{\mathrm{c}}$ is equal to $30 \mathrm{~N} / \mathrm{mm}^{2}, 50 \mathrm{~N} / \mathrm{mm}^{2}$ and $70 \mathrm{~N} / \mathrm{mm}^{2}$. In these cases the corresponding modulus of elasticity is $30000 \mathrm{~N} / \mathrm{mm}^{2}, \quad 34500 \mathrm{~N} / \mathrm{mm}^{2}$ and $37000 \mathrm{~N} / \mathrm{mm}^{2}$, the corresponding tensile strength $f_{\mathrm{c}}$ is $2 \mathrm{~N} / \mathrm{mm}^{2}, 3 \mathrm{~N} / \mathrm{mm}^{2}$ and $4 \mathrm{~N} / \mathrm{mm}^{2}$, the corresponding $u_{\mathrm{ck}}$ is $0.4 \mathrm{~mm}, 0.3 \mathrm{~mm}$ and 0 . $1 \mathrm{~mm}, L_{\mathrm{e}}$ is $50 \mathrm{~mm}$.

Curves in Fig. 5 and Fig. 6, were drawn with data calculated by the simplified method and the method in code.

It can be seen from Fig. 5 that the peak compressive strain of concrete in the simplified method is greater than the code value, but the residual strength values of the two are close. When $f_{\mathrm{c}}$ is equal to $70 \mathrm{~N} / \mathrm{mm}^{2}$, both peak compressive strain are close.

It can be seen from Fig. 6 that the value of descending stage of the simplified curve is greater obviously than the value of code. The reason is that the stress in code is a engineering stress which is less than the realistic stress. The stress of descending stage of the simplified curve is determined with the cracking width, and the value would be greater than the code value. 


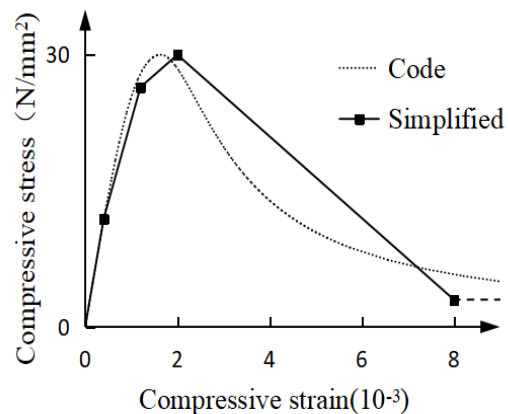

(a) $f_{\mathrm{c}}=30 \mathrm{~N} / \mathrm{mm}^{2}$

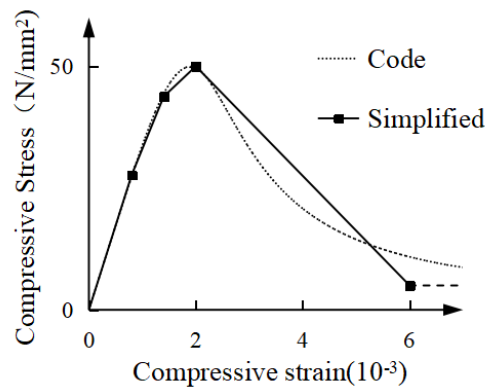

(b) $f_{\mathrm{c}}=50 \mathrm{~N} / \mathrm{mm}^{2}$

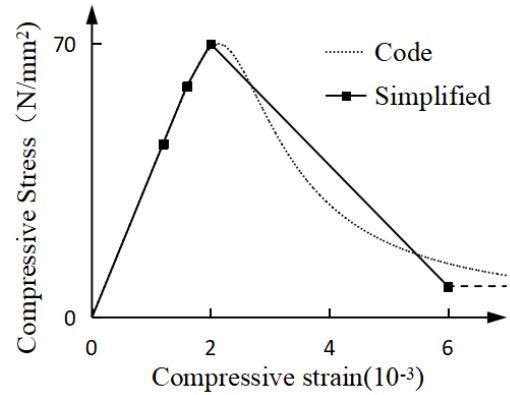

(c) $f_{\mathrm{c}}=70 \mathrm{~N} / \mathrm{mm}^{2}$

Fig. 5. The uniaxial compressive stress-strain curve

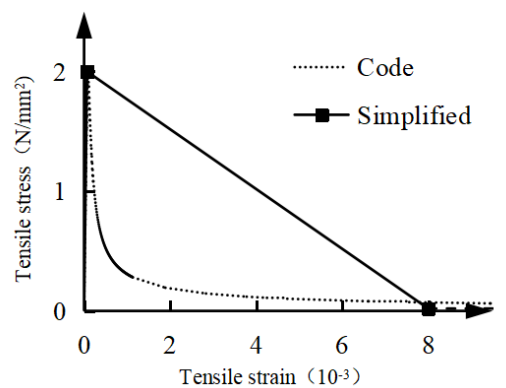

(a) $f_{\mathrm{t}}=2 \mathrm{~N} / \mathrm{mm}^{2}$

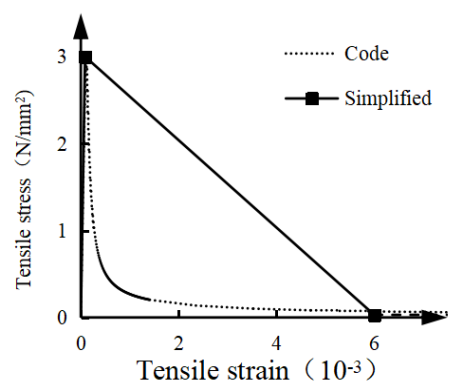

(b) $f_{\mathrm{t}}=3 \mathrm{~N} / \mathrm{mm}^{2}$

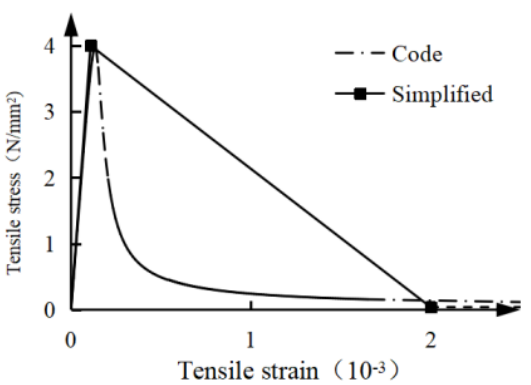

(c) $f_{\mathrm{t}}=4 \mathrm{~N} / \mathrm{mm}^{2}$

Fig. 6. The uniaxial tensile stress-strain curve

\section{Application of the simplified curve in simulation}

For verifying the effectiveness of the simplified curve, a conventional concrete beam and a high-strength concrete beam are chosen, in reference [13] and [14] respectively. Numerical analysis were carried out with CDP model in ABAQUS for both beams.

\section{1 Summary of models}

The size and reinforcement of specimens are shown in Fig. 7, Table1 and Table2. The average value of compressive strength for specimen LW2 is $47.8 \mathrm{~N} / \mathrm{mm}^{2}$, and the value for $\mathrm{L} 8$ is $93.3 \mathrm{~N} / \mathrm{mm}^{2}$.

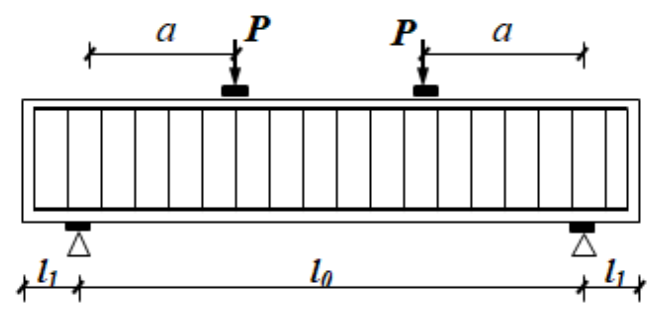

Fig. 7. The test model

Table 1. The size of specimens

\begin{tabular}{ccccc}
\hline $\begin{array}{c}\text { Serial } \\
\text { Number }\end{array}$ & $\begin{array}{c}\text { cross sectional } \\
\text { dimensions } / \mathrm{mm}\end{array}$ & $\begin{array}{c}l_{0} \\
/ \mathrm{mm}\end{array}$ & $\begin{array}{c}a \\
/ \mathrm{mm}\end{array}$ & $\begin{array}{c}l_{1} \\
/ \mathrm{mm}\end{array}$ \\
\hline LW2 & $200 \times 400$ & 3000 & 1000 & 250 \\
L8 & $200 \times 450$ & 3600 & 1230 & 200 \\
\hline
\end{tabular}

Table 2. The concrete grade and reinforcement

\begin{tabular}{ccccc}
\hline $\begin{array}{c}\text { Serial } \\
\text { Number }\end{array}$ & $\begin{array}{c}\text { Concret } \\
\text { e grade }\end{array}$ & $\begin{array}{c}\text { Lower } \\
\text { longitudin } \\
\text { al bar }\end{array}$ & $\begin{array}{c}\text { Upper } \\
\text { longit } \\
\text { Udinal } \\
\text { bar }\end{array}$ & Stirrup \\
\hline LW2 & C40 & $3 \Phi^{\mathrm{E}} 16$ & $2 \Phi^{\mathrm{E}} 12$ & $\Phi^{\mathrm{E}} 10 @ 150$ \\
L8 & $\mathrm{C} 80$ & $\begin{array}{c}1 \Phi^{\mathrm{F}} 20 \\
+2 \Phi^{\mathrm{F}} 25\end{array}$ & $2 \Phi^{\mathrm{F}} 12$ & $\$ 8 @ 200$ \\
\hline
\end{tabular}

In the FEM model, 8-node three-dimensional solid element C3D8R is used in concrete and 2-node truss element T3D2 is used in steel. The interaction between concrete and steel is simulated by EMBEDDED interaction.

\section{2 Properties of materials}

Because prism specimens can better reflect the actual compressive capacity of beams and columns than cube specimens, this paper selects the average compressive strength of prism as the strength representative value.

The conversion coefficients of cube compressive strength and prism compressive strength of specimens LW2 and L8 are 0.76 and 0.82 , respectively, and the corresponding prism compressive strength is $36.3 \mathrm{~N} / \mathrm{mm}^{2}$ and $76.5 \mathrm{~N} / \mathrm{mm}^{2}$.

Tensile strength, calculated by formula (10), is 2 . $84 \mathrm{~N} / \mathrm{mm}^{2}$ and $4.79 \mathrm{~N} / \mathrm{mm}^{2}$ respectively.

Young's Modulus of concrete is $32500 \mathrm{~N} / \mathrm{mm}^{2}$ and $38000 \mathrm{~N} / \mathrm{mm}^{2}$ respectively.

Poisson's ratio is 0.2 .

$$
f_{t}=0.395 f_{\mathrm{cm}}^{0.55}
$$

Where $f_{\mathrm{cm}}$ is the average compressive strength of cube 
$\left(\mathrm{N} / \mathrm{mm}^{2}\right)$.

The constitutive model of steel bars is bilinear kinematic hardening model. The yield strength is shown in [13] and [14]

When using the CDP model, the relationship between stress and strain needs to be transformed into the relationship between stress and inelastic strain $\left(\varepsilon_{\text {in }}\right)$ or cracking strain $\left(\varepsilon_{\mathrm{ck}}\right) . \varepsilon_{\text {in }}$ and $\varepsilon_{\mathrm{ck}}$ can be calculated by formula (11) or (12).

$$
\begin{gathered}
\varepsilon_{i n}=\varepsilon-\frac{\sigma_{c}}{E_{c}} \\
\varepsilon_{c k}=\varepsilon-\frac{\sigma_{t}}{E_{c}}
\end{gathered}
$$

Where compressive stress $\sigma_{\mathrm{c}}$ and tensile stress $\sigma_{\mathrm{t}}$ are values on the simplified curve.

Due to the monotonic loading, the influence of damage factor is not considered in the simulation.

\section{3 Result analysis}

Displacement control loading method is used in the calculation, and implicit finite element method is used.

The calculation is submitted on the PC equipped with i7CPU, and the calculation time of each model is about 10 minutes, and there is no non-convergence in the calculation process.

The curve between midspan deflection and load is shown in Fig. 8. Equivalent plastic strain in tension (PEEQT) of concrete and crack propagation of test model are shown in Fig 9 and Fig. 10.

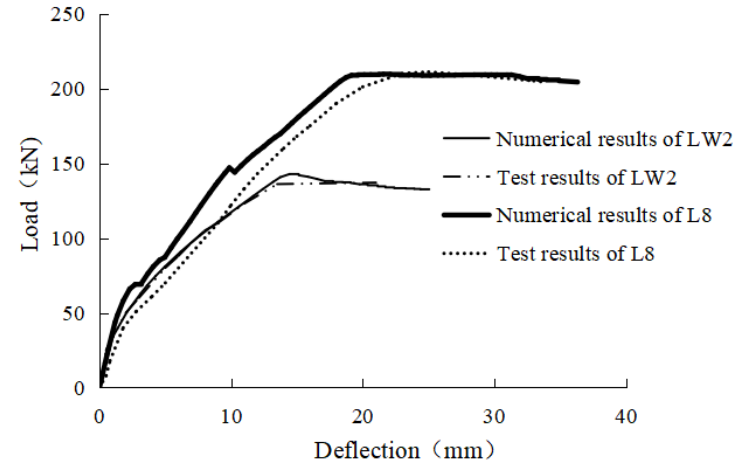

Fig. 8. The load-deflection curve

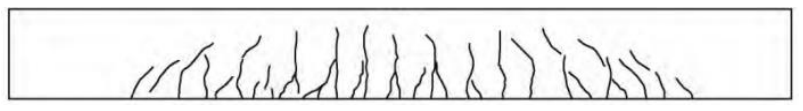

(a) The distribution of cracks in test specimen

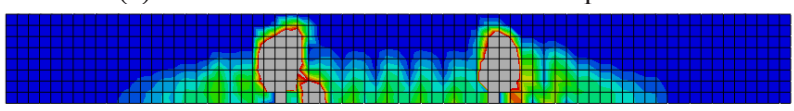

(b) The distribution of PEEQT

Fig. 9. The result comparison for specimen LW2

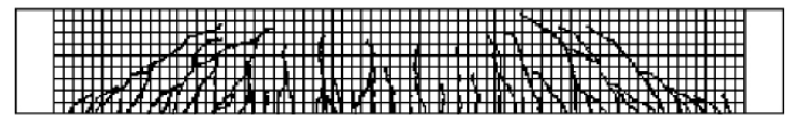

(a) The distribution of cracks in test specimen

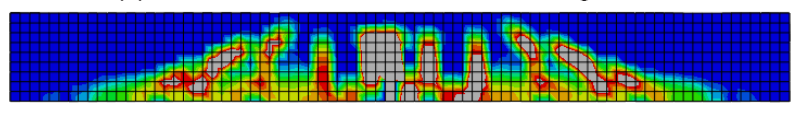

(b) The distribution of PEEQT

Fig. 10. The result comparison for specimen L8

Curves between midspan deflection and load show that the calculation results are generally consistent with the test results, but the peak load is slightly larger than the test value.

It can be seen from Fig. 9 and Fig. 10 that the calculation results of PEEQT is consistent with the crack distribution of the specimen.

\section{Conclusion}

Determining the constitutive model is a key procedure in numerical simulation of concrete structures. Uniaxial stress-strain curve is an important part of concrete constitutive model. This paper provided a simplified stress-strain curve of concrete that can be used in simulation.

According to the comparison between Chinese Code and the simplified curve, and application of the curve in numerical simulation, the following conclusions are obtained:

(1) the simplified stress-strain curve of uniaxial compression is close to the code value;

(2) the simplified stress-strain curve proposed in this paper has high computational efficiency and good convergence in the numerical simulation analysis of concrete structures.

\section{Acknowledges}

The author gratefully acknowledges supports for Science and Technology Research Project of Liaoning Provincial Department of Education in China (Grant No. QL201713, No. JL201913).

\section{References}

1. WATANARE E. Complete stress-strains curve for concrete in concentrical compression [J]. Mechanical Behavior of materials, 1972, 4: 153.

2. Cao Juyi. Stress-strain relationship of concrete [J]. Sichuan Building Science, 1979, 1: 1.

3. Guo Zhenhai, Zhang Xiuqin, Zhang Dacheng, etc. Experimental Investigation of the Complete Stress-Strain Curve of Concerer[J]. Journal of Building Structures, 1982, 3(1): 1.

4. Zhang Desi. Test Research on Complete Stress-Strain Curve of Concrete[J]. Journal of Hunan University (Natural Sciences) 1982, 9(4): 58.

5. Yang Muqiu, Lin Hong. Experimental study on 
tensile stress-strain curve of concrete under uniaxial compression[J]. Journal of Hydraulic Engineering, 1992, 6: 60 .

6. Design code for concrete structure: GB 50010-2010 [S]. Bei Jing: China Building Industry Press, 2011.

7. Yan Xiaohuan, Ren Xiaodan, Li Jie. Experimental Study of Full Process Variability of Concrete Under Uniaxial Compression[J]. Journal of Tongji University (Natural Science), 2015, 44(5): 664-670.

8. Shen $\mathrm{Pu}$ Sheng. Principles of Concrete Structure Design - 3rd Edition [M]. Higher Education Press, 2007.

9. Guo Zhenhai, Zhang Xiuquan. Experimental Investigation of Complete Stress-Deformation Curves of Concrete in Tension[J]. Journal of Building Structures, 1988, 9(4): 45-53.

10. Comite Euro-International Du Beton. CEB-FIP Model Code 1990[S]. London: Thomas Telford
Services Ltd, 1993.

11. Standard Specifications for Concrete Structures-2007 "Design" [S]. Tokyo: Japan Society of Civil Enginees, 2010.

12. Xu Lingyun, Zhu Tun, Ding Dajun. Experimental Study of Complete Tensile Stress-Strain Curves of Highstrength Concrete and Compact Reinforced Concrete[J]. Engineering Mechanics, 2001, 18(5): 36-42.

13. Chen Chen, Yang Xiaodong, Pan Wen, etc. Experimental research on flexural performance of reinforced concrete beams with $600 \mathrm{MPa}$ steel bars[J]. Building Structure, 2018(6): 1-4.

14. Ye Xianguo, Zhang Yu, Chong Xun, etc. Experimental study on shear behavior of simple supported high-strength concrete beams with high-strength steel[J]. Building Structure, 2013(8): 48-50. 